\title{
Empirical Evaluation of Social and Traditional Search Tools for Adhoc Information Retrieval
}

\author{
Safdar Hussain \\ Dept. of Computer Science and IT \\ The Islamia Univ. of Bahawalpur, \\ Pakistan
}

\author{
Malik Muhammad Saad Missen \\ Dept. of Computer Science and IT \\ The Islamia Univ. of Bahawalpur, \\ Pakistan
}

\author{
Nadeem Akhtar \\ Dept. of Computer Science and IT \\ The Islamia Univ. of Bahawalpur, \\ Pakistan \\ Mujtaba Husnain \\ Dept. of Computer Science and IT \\ The Islamia Univ. of Bahawalpur, \\ Pakistan
}

\author{
Intesab Hussain \\ Dept. of Computer System Eng. \\ Quaid e Awam Univ. \\ Nawabshah \\ M. Ali Nizamani \\ Faculty of Engineering, Science and \\ Tech., ISRA Univ. \\ Haiderabad
}

\begin{abstract}
The nature of World Wide Web (www) has evolved over the passage of time. Easier and faster availability of Internet has given rise to huge volumes of data available online. Another cause of huge volumes of data is the emergence of online social networks (like Facebook, Twitter, etc.) which has actually changed the role of data consumers to data generators. Increasing popularity of these online social networks has also changed the way different web services used to be used. For example, Facebook messaging has some impact on usage of emails; twitter usage affects (positively or negatively) online newspaper readings. Both of these platforms are heavily used for information searching. In this paper, we evaluate the role of Facebook and Twitter for academic queries and compare the findings with Google search engines to find out if there is a chance that these online social networks will replace Google sooner. A query set selected from the standard AOL dataset is used for experimentation. Academic related queries are selected and classified by expert users. Findings of Google, Facebook and Twitter are compared against these queries using Mean Average Precision (MAP), as a metrics for evaluation. Results conclude that Google has the dominating factor with a better MAP than Facebook and Twitter.
\end{abstract}

Keywords-AOL Query Log; Facebook; Twitter; Social Search

\section{INTRODUCTION}

With the passage of time, the nature of web has evolved. A major breakthrough in this regards is the emergence of online social networks. Online social networks have not only changed the role of users from content consumers to content generators but also have changed the way users used to search the web. These social media websites, showing various forms of consumer generated content (CGC) such as virtual communities, blogs, social networks, wikis, collaborative tagging and media files that are shared on sites like Flickr and YouTube have gained substantial popularity [1]. Also Social network sites (SNSs) such as Facebook, MySpace, Bebo, and Cyworld have attracted millions of users, many of whom have assimilated these sites into their daily practices in real time [2]. Apart of it, most sites support the maintenance of preexisting social networks, but others help strangers connect based on shared interests, activities, or political views.
Number of sites gratify to diverse audiences, while others attract people based on shared racial or common language, religious, sexual, or nationality-based identities. These sites also vary in extent to which they incorporate new communication and information tools, such as blogging, mobile connectivity, and photo/video-sharing [3]. This exponentially increasing interest in online social networks (see figure 1) has resulted in generation of huge amount of daily data on the web. Traditionally, it is know that search engines are used for searching relevant information from the web. However, there has been an increasing trend of searching information using online social networks. This is where the concept of social search gets emerged.

\section{A. Social Search}

The process of social search on social media points out the usage of social mechanism to seek information on web. Many search engines provide facility for social search; by providing a link of a web page (e.g., public Twitter posts), or it is simply a process of result ranking [4]. Social tagging systems' output can be the base platform for online social search engines like delicious on (delicious.com). Evan et al. [6] point out the stages for search process in cases when people' need to be in contact with others. Morris et al. [7] provide a survey for Twitter and Facebook users for the cases; to have a status message question type about any social networks need. The study of Social searching behavior, on a Q\&A site, is to post a question (e.g., Harper et al. [8], Liu et al. [9]) on community of large scale users (normally having no direct relation to the asker) can put answers. The systems like Aardvark which is simply a system of expertise-finding [10] or Collabio [[11]], straightaway can be useful to help in person finding process, and is qualified for information need consideration. Reference librarians can provide assistance as professionals to numerous searchers [12]. The social search asserts that (a) social network links can be leveraged to improve the quality of search results, and that (b) a growing body of Internet content cannot be retrieved by traditional web search as it is not wellconnected to the hyperlinked Web[14], [13]. It is said that current web search engines are not able to find relevant information available on online social networks. Therefore, 
there is a trend of using online social networks for information seeking. In this work, we focus to analyze this trend by looking at the relevancy of the results both kind of search tools return. We try to find out how much successful are online social networks on providing relevant results and if there is any chance of online social networks replacing traditional search engines. We select a set of academic queries for this purpose because academic queries are one of the most searched information on online social networks. The overall prime objective of this work is to compare and evaluate the effectiveness of online social networks and traditional search engines for search of academic queries. A diversity of topics is selected from a standard query log that relates to different academic information needs.

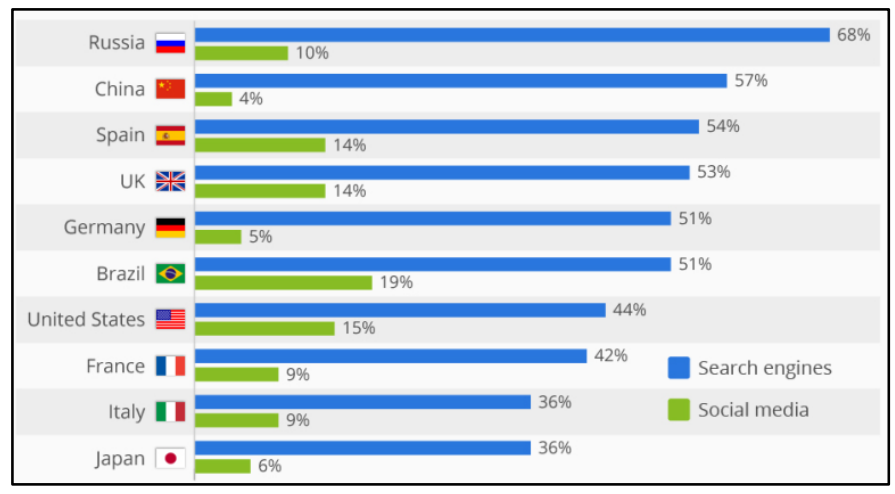

Fig. 1. Search Engines Vs Online Social Networks

The paper is categorized in different sections like: Section II, contains some related literature work while section III portrays experiments and discuss their results. At the end, we conclude our paper with conclusions drawn from our work.

\section{RELATED WORK}

Most of the other works typically focus on social search. For example, Dodds et al. [16] report a successful experiment on exploration of social search. Experiments performed in which more than 60,000 email users attempted to reach one of the 18 target persons in 13 countries by forwarding messages to acquaintances. It was found that targets can be grasped in a median of 5 to 7 steps. Another work which tries to improve web search using social aspects is done by Bao et al. [17]. They used social annotations for this purpose. Some have also analyzed the impact of users social networks on personalization [18]. There are works that have evaluated some specific online social network and evaluated them for social search. For example, Scale et al. [21] evaluate the role of Facebook platform as a social search engine. They found out that Facebook returns irrelevant results for unknown persons or groups. Another very popular work in this regard has been performed by Tancer [22]. Tancer put in front a case study of a user information need, the solution in which is delivered by friends in Facebook relieving the users' use of a traditional search engine. Tancers experience concludes insight in how humans in a Social Networking Sites (SNS) environment can collaborate and participate to meet user information needs. One of the most important contributions towards social search is proposal of models for social search. Work of Evan et al. [19], [20] is considered a significant effort in this regard. According to Jaime Teevan et al. [23], roundabout $50 \%$ users are in contact via the use of Status Message Question Asking(SMQA) behavior, so that is the reason that SMQA is the hot research area and most common item in new researches. After 50\% Facebook users, twitter was on second with $33 \%$ and LinkedIn, Google with $25 \%$ on third in usage of SMQA. There are some works that we find very relevant to our work in nature of the problem they worked on. The work of Morris et al. is one of the initial works [15] focusing on social search. This work is most related to our work however there are major differences between our methodology and target domains. Compared to our work where we effectively use SNs online search option, they used status messages as information seeking option. Similarly, Zheng et al. [24] tried to evaluate online social networks for travel queries. The focus and goal of their study was to examine the extent to which social media results appear in search engine results in the context of travel-related searches. Their employed research design simulated a traveler's use of a search engine; it was for travel planning by using a set of pre-defined keywords in combination with nine U.S. tourist destination names. Comparative findings of search results reveal that the role play of social media contains significant portion of the search results, as now people' rely \& use social media community more than ever before. The current work is the confirmation to argue that social media provides online search progressively. Another work that we find somehow close to our work is done by Alan et al. [25]. In current paper, authors examined the work potential for using online social networks to boost Internet search. They analyzed the differences between the social networking systems and Web in terms of the mechanisms they use to locate and publish useful information. They conferred the benefits of integrating the mechanisms for finding useful content in both the social networks and Web. Such initial results from a social networking experiment suggest that such integration has the potential to improve the quality of Web search experience. Our work portrays the results by evaluating the situations in which platforms are suitable for what type of categories on different platforms like Google, Facebook \& Twitter.

\section{EXPERIMENTS}

Our experimentation significantly follows standard methods and measures. Experiments start with selection of academic queries [26]. We consider a query an academic query if it seeks any information relating to academics needs (for example, from admission information search to expert searching). We use real world search engine query log for extraction of academic queries.

\section{A. Selection of Queries}

On August 4, 2006 (in first decade of century), AOL (America Online) intuitively released a huge dataset query log collection (i.e. of 500,000 people') that was the collection of real users search relation with AOL for academic (noncommercial) domain. AOL, take an action and immediately (on August 7, 2006) cleared the site with such data, but it was too late. The files were floated and shared all over the internet within this short time span. It was bulk of about 36 million Web searched queries typed by approximately 657,000 users 
for three month time span (from March 01, 2006, to May 31, 2006). It consisted of a compressed $439 \mathrm{MB}$ download with $2.12 \mathrm{~GB}$ in expansion. A sequential go through AOL dataset makes it possible for us to select a subset of academic queries. We identify and further categorized these queries under different information need labels to make them more understandable. Table1 gives 36 queries for 6different information needs are given in the table below.

\section{TABLE. I. CATEGORIES AND THEIR QUERIES}

\begin{tabular}{|c|c|c|}
\hline $\begin{array}{l}\text { Sr. } \\
\text { No }\end{array}$ & Categories & Queries \\
\hline 1 & $\begin{array}{l}\text { Research } \\
\text { Papers }\end{array}$ & $\begin{array}{l}\text { - how to write research paper introduction } \\
\text { thesis hypothesis, } \\
\text { - } \quad \text { thesis statements research papers, } \\
\text { - } \quad \text { technical writing research paper tips, } \\
\text { - } \quad \text { how to cite your information in your research } \\
\text { paper, } \\
\text { - } \quad \text { bibliography for research paper, } \\
\text { - }\end{array}$ \\
\hline 2 & $\begin{array}{l}\text { Distance } \\
\text { Learning }\end{array}$ & $\begin{array}{l}\text { University that offers PhD program from } \\
\text { distance learning, } \\
\text { - } \\
\text { Pros \& cons for distance learning in high } \\
\text { school, } \\
\text { - } \\
\text { Distance learning education council, } \\
\text { - } \\
\text { Army distance learning, } \\
\text { Distance learning undergraduate degree } \\
\text { universities, } \\
\text { Virtual classes distance learning online } \\
\text { courses. }\end{array}$ \\
\hline 3 & $\begin{array}{l}\text { Research } \\
\text { Topics }\end{array}$ & $\begin{array}{l}\text { What is meant by Educational Research } \\
\text { Topics? Enlist them and explain, } \\
\text { - What is the process for choosing a research } \\
\text { topic? Discuss some key points? } \\
\text { - Name the topics for a good research paper. } \\
\text { Briefly tell about all of them as well, } \\
\text { - What are current research topics? } \\
\text { - Hpecifically in computer science, } \\
\text { How to perform qualitative research on any } \\
\text { topic? Explain, } \\
\text { - Terrorism topic for research paper. }\end{array}$ \\
\hline 4 & $\begin{array}{l}\text { Scholarship } \\
\text { Program }\end{array}$ & $\begin{array}{l}\text { - How to get easy scholarships for computer } \\
\text { science PhD program? } \\
\text { - What are 21st century scholarship programs? } \\
\text { - What do you know about Bill Gates } \\
\text { scholarship program? Comment, } \\
\text { - What is National Merit Scholarship Program? }\end{array}$ \\
\hline
\end{tabular}

\begin{tabular}{|c|c|c|}
\hline & & $\begin{array}{l}\text { - What is Microsoft scholarship program? } \\
\text { - What is California state scholarship program? }\end{array}$ \\
\hline 5 & $\begin{array}{l}\text { University } \\
\text { Programs }\end{array}$ & $\begin{array}{l}\text { What are Colorado technical university } \\
\text { computer science programs? } \\
\text { - What is New York university summer } \\
\text { program? Any detail, } \\
\text { What are Columbia university PhD } \\
\text { programs? Any detail, } \\
\text { - What are university travel study programs? } \\
\text { Comment about it, } \\
\text { What is Oxford university summer program? } \\
\text { Any detail, } \\
\text { What are Texas southern university } \mathrm{PhD} \\
\text { programs? Comment about it. }\end{array}$ \\
\hline 6 & $\begin{array}{l}\text { Research } \\
\text { Institutes }\end{array}$ & $\begin{array}{l}\text { - What is the Christian research institute? } \\
\text { - What are National research institutions in } \\
\text { Pakistan? Write detail, } \\
\text { - } \\
\text { - Slectric power research institute in Pakistan, } \\
\text { - Whathwest research institute, } \\
\text { institute? Comment, } \\
\text { What is Virtual research institute? Describe } \\
\text { about it. }\end{array}$ \\
\hline
\end{tabular}

The queries given in Table 1 are used to compare search engines with online social networks. We select three different platforms for performing our experiments. We choose Google to represent Search Engines while Facebook and Twitter are chosen for representing online social networks. This selection is based on the popularity of each platform (see figure 1) that can be used for textual information search.

\section{B. Returned Results and Evaluations}

In next phase of experimentation, we use search interface of each selected platform to search with selected list of queries (see table 1). Top 20 documents for each query are downloaded for each selected platform as it is shown in figures 2, 3 and 4 . To evaluate these returned results, a massive exercise of user evaluation is planned.

\section{User Evaluations}

We recruit five different users for unbiased evaluation of returned results foreach platform. Each user is aged between 24 to 30 years and is computer science graduates. Users are asked to thoroughly understand the queries for unbiased evaluation of returned results. They are presented with a web interfaceto mark each returned result as relevant (1) or not relevant (0). Evaluationsare performed in a sequential process i.e. first of all results of all queries areevaluated for Google and then same process is repeated for Twitter and Facebook. Fleiss kappa [27] is used to measure inter-annotator agreement for eachselected platform as shown in table 2 . We can see that results are good enough to be considered as a reliable interannotator agreement. 
TABLE. II. MAP FOR GOOGLE PLATFORM

\begin{tabular}{|c|c|c|c|c|c|}
\hline \multirow{2}{*}{ Queries } & \multicolumn{5}{|l|}{ Users } \\
\hline & User-1 & User-2 & User-3 & User-4 & User-5 \\
\hline \multicolumn{6}{|c|}{ Category - I (Research Papers) } \\
\hline Q1 & 0.82 & 0.88 & 0.94 & 0.89 & 0.90 \\
\hline Q2 & 0.88 & 0.84 & 0.94 & 0.94 & 0.94 \\
\hline Q3 & 0.73 & 0.80 & 0.76 & 0.79 & 0.80 \\
\hline Q4 & 1 & 1 & 1 & 1 & 1 \\
\hline Q5 & 1 & 0.95 & 1 & 1 & 1 \\
\hline Q6 & 1 & 1 & 1 & 1 & 1 \\
\hline MAP/User & 0.91 & 0.91 & 0.94 & 0.94 & 0.94 \\
\hline \multicolumn{6}{|c|}{ Category - II (Distance Learning) } \\
\hline Q7 & 0.95 & 0.94 & 0.95 & 0.95 & 0.95 \\
\hline Q8 & 0.72 & 0.63 & 0.78 & 0.79 & 0.84 \\
\hline Q9 & 1 & 1 & 1 & 1 & 1 \\
\hline Q10 & 0.74 & 0.83 & 0.82 & 0.82 & 0.84 \\
\hline Q11 & 0.95 & 1 & 0.95 & 0.95 & 0.95 \\
\hline Q12 & 0.85 & 0.94 & 0.89 & 0.90 & 0.90 \\
\hline MAP/User & 0.87 & 0.89 & 0.90 & 0.90 & 0.91 \\
\hline \multicolumn{6}{|c|}{ Category - III (Research Topics) } \\
\hline Q13 & 0.73 & 0.67 & 0.79 & 0.80 & 0.80 \\
\hline Q14 & 0.90 & 0.90 & 0.90 & 0.90 & 0.90 \\
\hline Q15 & 0.79 & 0.75 & 0.88 & 0.84 & 0.85 \\
\hline Q16 & 0.89 & 0.89 & 0.90 & 0.90 & 0.90 \\
\hline Q17 & 0.83 & 0.88 & 0.85 & 0.85 & 0.85 \\
\hline Q18 & 0.88 & 0.89 & 0.88 & 0.89 & 0.90 \\
\hline MAP/User & 0.84 & 0.83 & $\mathbf{0 . 8 7}$ & 0.86 & 0.87 \\
\hline \multicolumn{6}{|c|}{ Category - IV (Scholarship Program) } \\
\hline Q19 & 1 & 1 & 1 & 1 & 1 \\
\hline Q20 & 1 & 1 & 1 & 1 & 1 \\
\hline Q21 & 0.89 & 0.90 & 0.89 & 0.89 & 0.90 \\
\hline Q22 & 1 & 1 & 1 & 1 & 1 \\
\hline Q23 & 0.88 & 0.88 & 0.89 & 0.89 & 0.89 \\
\hline Q24 & 0.94 & 0.94 & 0.95 & 0.95 & 0.95 \\
\hline MAP/User & 0.95 & 0.95 & 0.96 & 0.96 & 0.96 \\
\hline \multicolumn{6}{|c|}{ Category - V (University Programs) } \\
\hline Q25 & 0.94 & 0.95 & 0.89 & 0.89 & 0.89 \\
\hline Q26 & 0.90 & 0.95 & 0.90 & 0.90 & 0.90 \\
\hline Q27 & 1 & 1 & 1 & 1 & 1 \\
\hline Q28 & 1 & 1 & 1 & 1 & 1 \\
\hline Q29 & 0.95 & 0.90 & 0.95 & 0.95 & 0.95 \\
\hline Q30 & 1 & 1 & 1 & 1 & 1 \\
\hline MAP/User & 0.97 & 0.97 & 0.96 & 0.96 & 0.96 \\
\hline \multicolumn{6}{|c|}{ Category - VI (Research Institutes) } \\
\hline Q31 & 0.94 & 0.95 & 0.89 & 0.90 & 0.90 \\
\hline Q32 & 0.95 & 0.95 & 0.90 & 0.90 & 0.90 \\
\hline Q33 & 0.89 & 0.89 & 0.94 & 0.95 & 0.95 \\
\hline Q34 & 1 & 1 & 1 & 1 & 1 \\
\hline Q35 & 1 & 1 & 1 & 1 & 1 \\
\hline Q36 & 0.83 & 0.83 & 0.85 & 0.85 & 0.85 \\
\hline MAP/User & 0.94 & 0.94 & 0.93 & 0.93 & 0.93 \\
\hline
\end{tabular}

TABLE. III. COMPARISON OF MAPS FOR ALL PLATFORMS (GOOGLE, TWITTER, FACEBOOK)

\begin{tabular}{|c|c|c|c|c|}
\hline & & Google & Twitter & Facebook \\
\hline & Q1 & 0.89 & 0.49 & 0.65 \\
\hline & Q2 & 0.91 & 0.45 & 0.65 \\
\hline Category - I & Q3 & 0.78 & 0.79 & 0.47 \\
\hline & Q4 & 1 & 0.95 & 0.42 \\
\hline & Q5 & 0.99 & 0.39 & 0.31 \\
\hline & Q6 & 1 & 0.35 & 0.12 \\
\hline MAP Per Cate & & 0.93 & 0.57 & 0.44 \\
\hline & Q7 & 0.95 & 1 & 0.63 \\
\hline & Q8 & 0.75 & 0.70 & 0.74 \\
\hline Category -I I & Q9 & 1 & 0.69 & 0.74 \\
\hline & Q10 & 0.81 & 0.05 & 0.70 \\
\hline & Q11 & 0.96 & 0.67 & 0.56 \\
\hline & Q12 & 0.90 & 0.63 & 0.76 \\
\hline MAP Per Cate & & 0.90 & 0.62 & 0.69 \\
\hline & Q13 & 0.76 & 0.42 & 0.40 \\
\hline & Q14 & 0.90 & 0.55 & 0.61 \\
\hline Category -III & Q15 & 0.82 & 0.48 & 0.66 \\
\hline & Q16 & 0.90 & 0.65 & 0.55 \\
\hline & Q17 & 0.85 & 0.25 & 0.50 \\
\hline & Q18 & 0.89 & 0.33 & 0.58 \\
\hline MAP Per Cate & & 0.85 & 0.45 & 0.55 \\
\hline & Q19 & 1 & 0.72 & 0.36 \\
\hline & Q20 & 1 & 0 & 0.53 \\
\hline Category -IV & Q21 & 0.90 & 0.47 & 0.55 \\
\hline & Q22 & 1 & 0 & 0.54 \\
\hline & Q23 & 0.89 & 0.71 & 0.42 \\
\hline & Q24 & 0.95 & 1 & 0.48 \\
\hline MAP Per Cate & & 0.96 & 0.48 & 0.48 \\
\hline & Q25 & 0.92 & 0 & 0.66 \\
\hline & Q26 & 0.91 & 0.58 & 0.51 \\
\hline & Q27 & 1 & 0.61 & 0.56 \\
\hline & Q28 & 1 & 0.68 & 0.50 \\
\hline Category -V & Q29 & 0.94 & 0.56 & 0.54 \\
\hline & Q30 & 1 & 0 & 0.43 \\
\hline MAP Per Cate & & 0.96 & 0.40 & 0.53 \\
\hline & Q31 & 0.92 & 0.44 & 0.62 \\
\hline & Q32 & 0.92 & 0.53 & 0.60 \\
\hline Category-VI & Q33 & 0.92 & 0.40 & 0.65 \\
\hline & Q34 & 1 & 0.37 & 0.49 \\
\hline & Q35 & 1 & 0.54 & 0.50 \\
\hline & Q36 & 0.84 & 0.38 & 0.61 \\
\hline MAP Per Cate & & 0.93 & 0.44 & 0.58 \\
\hline
\end{tabular}

We decided the usage of mean average precision (MAP) [28] as metric for performance evaluation of each platform. In a set of queries, the MAP is the mean of the average precision scores for each query. 


$$
M A P=\frac{\sum_{q=1}^{Q} A P(q)}{Q}
$$

Where $\mathrm{Q}$ is the total number of queries and $\mathrm{AP}(\mathrm{q})$ is average precision for a given query $\mathrm{q}$.

To compute average precision, it is assumed that we have total twenty relevant documents in the collection for each query. Following tables provide MAP for each selected platform computed through labeling by each user. Looking at individual results for Google (figure 2), Facebook and Twitter, it can be concluded that MAP results for Google are the highest and consistent across different categories as well as different users. MAP values for Twitter are much lower but consistent across different categories and users. However, for Facebook results we see inconsistency among users as well as among categories. Comparing MAP results for all three platforms using figure 2, we can conclude that Google has produced the best results for all academic queries while Facebook has beaten Twitter for most of the categories.

TABLE. IV. FleISS KAPPA FOR DifFERENT PlatFormS

\begin{tabular}{|l|l|l|}
\hline $\begin{array}{l}\text { Sr. } \\
\text { No }\end{array}$ & Platform & Fleiss Kappa \\
\hline 1 & Google & 0.79 \\
\hline 2 & Twitter & 0.70 \\
\hline 3 & Facebook & 0.73 \\
\hline
\end{tabular}

TABLE. V. VARIANCE COMPARISONS

\begin{tabular}{|l|l|l|l|}
\hline $\begin{array}{l}\text { Sr. } \\
\text { No }\end{array}$ & Platform & $\begin{array}{l}\text { Variance } \\
\text { Among Users }\end{array}$ & $\begin{array}{l}\text { Variance } \\
\text { Among } \\
\text { Categories }\end{array}$ \\
\hline 1 & Google & 0.0001 & 0.001 \\
\hline 2 & Twitter & 0.001 & 0.007 \\
\hline 3 & Facebook & 0.004 & 0.007 \\
\hline
\end{tabular}

Table 5 shows the variance among MAP for users and also for categories which also show that Google result show more consistent attitude for all query types. Therefore, it can be concluded from all results that Google still holds its position for academic information searching. However, there is a trend of seeking support of online social networks for search information which did not exist earlier. We also observed that Facebook proved to be more helpful when searching for academic related information than Twitter. Main reason for these results is presence of many Facebook pages and groups that share much academic related information such as admissions and scholarship opportunities.

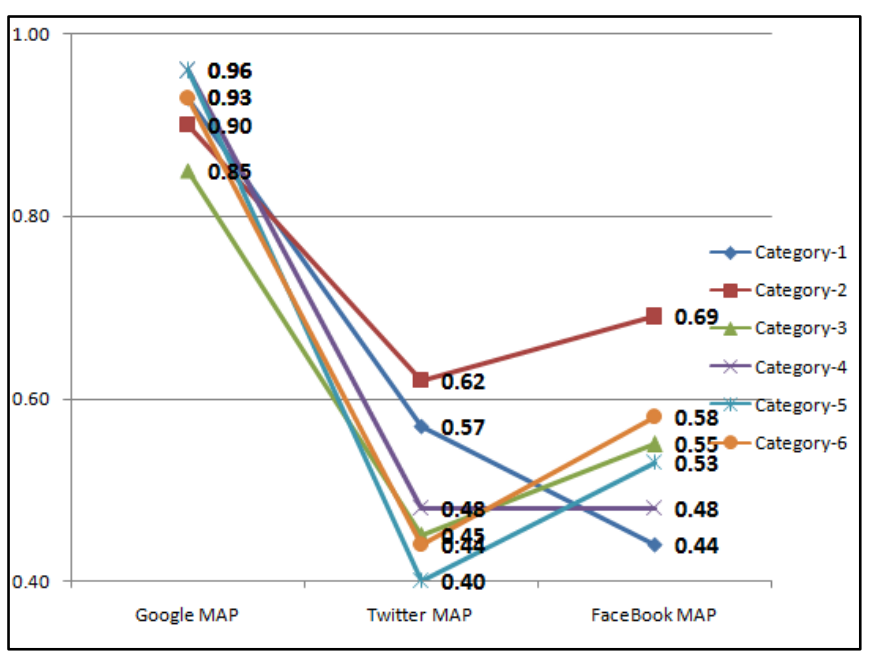

Fig. 2. MAP Comparison of Google, Twitter and Facebook for all Query categories

\section{CONCLUSION}

In this paper, we made an effort to compare social search with traditional search for academic queries. The main objective was to evaluate who is better after years of dominance of online social networks among web users. For this purpose, we selected Facebook and Twitter for representing online social networks while Google search engine is used for representation of traditional search. We used AOL data-set for selection of queries. The experimentation results reveal that Google maintains its dominance in academic information searching. Comparing both Facebook and Twitter, it has been found that Facebook provides much more relevant information for academic queries to its users than Twitter.

\section{REFERENCES}

[1] Lewandowski, Dirk, ed. Web search engine research. Emerald Group Publishing Limited, 2012.

[2] Ramage, Magnus. Online communication and collaboration: A reader. Routledge, 2010.

[3] Ellison, Nicole B. "Social network sites: Definition, history, and scholarship." Journal of Computer-Mediated Communication 13.1 (2007): 210-230.

[4] Smyth, Barry, et al. "Google shared. a case-study in social search." International Conference on User Modeling, Adaptation, and Personalization. Springer Berlin Heidelberg, 2009.

[5] Morris, Meredith Ringel, Jaime Teevan, and Steve Bush. "Enhancing collaborative web search with personalization: groupization, smart splitting, and group hit-highlighting." Proceedings of the 2008 ACM conference on Computer supported cooperative work. ACM, 2008.

[6] Evans, Brynn M., and Ed H. Chi. "Towards a model of understanding social search." Proceedings of the 2008 ACM conference on Computer supported cooperative work. ACM, 2008.

[7] Morris, Meredith Ringel, Jaime Teevan, and Katrina Panovich. "What do people ask their social networks, and why?: a survey study of status 
message q\&a behavior." Proceedings of the SIGCHI conference on Human factors in computing systems. ACM, 2010.

[8] Harper, F. Maxwell, et al. "Predictors of answer quality in online Q\&A sites." Proceedings of the SIGCHI Conference on Human Factors in Computing Systems. ACM, 2008..

[9] Liu, Yandong, Jiang Bian, and Eugene Agichtein. "Predicting information seeker satisfaction in community question answering." Proceedings of the 31st annual international ACM SIGIR conference on Research and development in information retrieval. ACM, 2008.

[10] Horowitz, Damon, and Sepandar D. Kamvar. "The anatomy of a largescale social search engine." Proceedings of the 19th international conference on World wide web. ACM, 2010.

[11] Bernstein, Michael, et al. "Collabio: a game for annotating people within social networks." Proceedings of the 22nd annual ACM symposium on User interface software and technology. ACM, 2009.

[12] Taylor, Robert S. "Question-negotiation and information seeking in libraries." College \& research libraries 29.3 (1968): 178-194.

[13] Nextmedia, C. S. A. "Social networks overview: Current trends and research challenges." European Commission Information Society and Media (2010)

[14] Tsou, Ming-Hsiang, et al. "Mapping social activities and concepts with social media (Twitter) and web search engines (Yahoo and Bing): a case study in 2012 US Presidential Election." Cartography and Geographic Information Science 40.4 (2013): 337-348.

[15] Morris, Meredith Ringel, Jaime Teevan, and Katrina Panovich. "A Comparison of Information Seeking Using Search Engines and Social Networks." ICWSM 10 (2010): 23-26..

[16] Dodds, Peter Sheridan, Roby Muhamad, and Duncan J. Watts. "An experimental study of search in global social networks." science 301.5634 (2003): 827-829.

[17] Bao, Shenghua, et al. "Optimizing web search using social annotations."
Proceedings of the 16th international conference on World Wide Web. ACM, 2007.

[18] Carmel, David, et al. "Personalized social search based on the user's social network." Proceedings of the 18th ACM conference on Information and knowledge management. ACM, 2009.

[19] Evans, Brynn M., and Ed H. Chi. "An elaborated model of social search." Information Processing \& Management 46.6 (2010): 656-678.

[20] Evans, Brynn M., and Ed H. Chi. "Towards a model of understanding social search." Proceedings of the 2008 ACM conference on Computer supported cooperative work. ACM, 2008.

[21] Scale, Mark-Shane. "Facebook as a social search engine and the implications for libraries in the twenty-first century." Library Hi Tech 26.4 (2008): 540-556.

[22] Tancer, Bill. "Is Facebook the future of search?." Time magazine (2008).

[23] Oeldorf-Hirsch, Anne, et al. "To search or to ask: the routing of information needs between traditional search engines and social networks." Proceedings of the 17th ACM conference on Computer supported cooperative work \& social computing. ACM, 2014.

[24] Xiang, Zheng, and Ulrike Gretzel. "Role of social media in online travel information search." Tourism management 31.2 (2010): 179-188.

[25] Mislove, Alan, Krishna P. Gummadi, and Peter Druschel. "Exploiting social networks for internet search." 5th Workshop on Hot Topics in Networks (HotNets06). Citeseer. 2006.

[26] Ellis, David. "Modeling the information-seeking patterns of academic researchers: A grounded theory approach." The Library Quarterly 63.4 (1993): 469-486

[27] Fleiss, Joseph L. "Measuring nominal scale agreement among many raters." Psychological bulletin 76.5 (1971): 378.

[28] Zhu, Mu. "Recall, precision and average precision." Department of Statistics and Actuarial Science, University of Waterloo, Waterloo 2 (2004): 30 . 